\title{
Currículo y pandemia: Tiempo de crisis y oportunidad de innovación disrupción
}

\author{
Curriculum and Pandemic: Time of Crisis and Opportunity for Disruption \\ Currículo e pandemia: Tempo de crise e oportunidade para inovação disruptiva
}

Frida Díaz-Barriga-Arceo

Universidad Nacional Autónoma de México

Facultad de Psicología

Ciudad de México, México

diazfrida@prodigy.net.mx

https://orcid.org/0000-0001-8720-1857

María Concepción Barrón-Tirado

Universidad Nacional Autónoma de México

Instituto de Investigaciones sobre la Universidad y la Educación

Ciudad de México, México

barront@unam.mx

(iD) https://orcid.org/0000-0003-4214-9228

Resumen: Se discute la estrategia de educación en casa en la virtualidad, en términos de la desigualdad imperante y el enfoque transmisivo adoptado. Asimismo, se habla de algunos caminos de innovación disruptiva en el campo del currículo escolar.

Palabras clave: Educación virtual en casa; innovación disruptiva; currículo escolar; COVID-2019.

Abstract: The virtual homeschooling strategy is discussed in terms of prevailing inequality and the transmissive approach adopted. Likewise, it talks about some paths of disruptive innovation in the field of the school curriculum.

Keywords: Virtual homeschooling; disruptive innovation; school curriculum; COVID-19.

Resumo: A estratégia de educação escolar em casa virtual é discutida em termos da desigualdade prevalecente e da abordagem transmissiva adotada. Da mesma forma, fala sobre alguns caminhos de inovação disruptiva no campo do currículo escolar.

Palavras-chave: Educação domiciliar virtual; inovação disruptiva; currículo escolar; COVID-19.

Recibido: 07/11/2020 Aceptado: 18/11/2020 
https://doi.org/10.15359/ree.24-S.3

https://www.revistas.una.ac.cr/index.php/educare

educare@una.ac.cr

\section{Introducción}

El hito histórico en el que nos encontramos inmersos avizora una nueva realidad social, que de ninguna manera debe enmarcarse en la nostalgia por volver al pasado. La pandemia COVID-19 ha evidenciado que la adopción de políticas y estilos de vida propias del contrato social neoliberal han provocado la mayor erosión al bienestar público en salud y educación, así como en la seguridad y ecología. A pesar de varias décadas de impulso a reformas educativas nacionales, no se ha consolidado la formación ciudadana, la capacidad de pensar y actuar con autonomía y criticidad, tampoco la práctica genuina de la inclusión y aceptación del diferente, ni de aquellos saberes que se ha pregonado se requieren para configurar las identidades del presente milenio, incluyendo la literacidad digital. Según informó la UNESCO (2020), a mediados de marzo más de 849 millones de niños, niñas y jóvenes se encontraban confinados en casa, dado que más de 113 países habían cerrado a nivel nacional escuelas y universidades mientras que la tendencia seguía en aumento. Los sistemas educativos optaron en su mayoría por un esquema de traslado de la educación presencial a la virtualidad, para lo cual se habilitaron plataformas y aplicaciones tecnológicas, bajo la consigna de lograr el cumplimiento de planes y programas de estudio, para que no se perdiera el ciclo escolar.

Los resultados no se hicieron esperar y pronto aparecieron voces críticas de las medidas tomadas en tal situación emergente e inédita, para la que nadie parecía estar preparado. Todos aquellos aspectos que han configurado de manera clásica el currículo escolar, fines, objetivos, contenidos, métodos didácticos, evaluación, se comenzaron a poner en tela de juicio ¿Acaso lo más relevante era cubrir contenidos disciplinares, por lo general excesivos, que en un momento tan crítico estaban tan alejados de la realidad de los educandos y sus comunidades?, ¿se estaba haciendo un empleo pedagógico y con sentido de tales tecnologías digitales o sólo un tratamiento técnico para poner en pantalla textos e imágenes en un esquema comunicativo unidireccional?, ¿quiénes tenían acceso a esta opción de educación virtual en casa, con qué resultados?, ¿qué sucedía con los agentes educativos? Quedó en evidencia que, a pesar del gran esfuerzo por trasladar el currículo a la virtualidad, no era cuestión de un ajuste a la modalidad en línea, sobre todo si esta se entendía en la misma lógica de la transmisión-recepción de contenidos. De entrada, se tuvo que reconocer que el sistema educativo en general, y las estructuras curriculares en particular, operan en nuestro contexto de manera inequitativa, no inclusiva, contraviniendo los preceptos de la justicia social y curricular.

Sabemos que América Latina es la región más desigual del planeta, incluso si se compara con el sur de África o el este de Asia, y mucho más que los países desarrollados (Cuenca, 2012). De ahí que los colectivos con mayor riesgo de exclusión educativa son los pobres, los indígenas, 
https://doi.org/10.15359/ree.24-S.3

las personas del medio rural o de zonas marginadas, las mujeres y quienes tienen alguna discapacidad, en su calidad de poblaciones residuales de un sistema educativo que opera la desigualdad y discriminación, aunque a la letra en los programas curriculares se diga lo opuesto.

Lo antes dicho se recrudece si se suma el factor de acceso a las tecnologías digitales. En el Congreso Latinoamericano de Comunicaciones celebrado en Córdoba Argentina en junio de 2019, se informó que "el 45\% de los latinoamericanos no tiene acceso a los servicios derivados de la conectividad digital, tales como telemedicina, teleducación, gobierno en línea y banca electrónica, entre otros" (Corporación Andina de Fomento [CAF], 2019, párr. 3). De ahí que casi la mitad del estudiantado no podría acceder a la educación virtual.

En el caso de aquellos que lograron el acceso, tanto docentes como educandos comenzaron a reportar experiencias poco significativas en la virtualidad, la carencia de habilidades para el aprendizaje autónomo, la ausencia de mediación docente, el exceso de tareas y actividades repetitivas y poco motivantes, o bien la falta de formación docente. Evidencia de que nos falta mucho en la formación de competencias digitales, capacidad de aprender a aprender, didácticas innovadoras y evaluación auténtica. Desafortunadamente, no ha permeado la idea de que las tecnologías digitales son ante todo artefactos culturales con un sentido social e histórico, que no son soluciones en sí mismas, y que diversos usos en la interacción humana encaminados al aprendizaje profundo y significativo, son los que permiten explorar su potencial como instrumento de mediación en los planos semiótico y psicológico, así como en la creación conjunta y distribuida del conocimiento. Asimismo, para que una experiencia de aprendizaje en línea sea propicia, se requiere la debida presencia docente, participación social, promoción de cognición, emociones y aprendizaje significativo, además de ayudas ajustadas y dispositivos pedagógicos centrados en las necesidades de los aprendices (Garrison y Anderson, 2005).

\section{En pro de la innovación curricular disruptiva}

Este momento de crisis abre la oportunidad de construir nuevos ambientes educativos, otra mirada de educabilidad y la firme intención de promover la innovación disruptiva de estructuras y prácticas curriculares. No se trata de mejorar lo ya existente, sino de atreverse a cambios de fondo, en estructuras, procesos de gestión, posicionamiento de los actores de la educación. La innovación disruptiva requiere cambiar mentalidades y prácticas, un proceso de destrucción creadora, el arribo a nuevos paradigmas.

Aunque no es fácil perfilar la visión de lo que se requiere dada la incertidumbre imperante, es evidente que el currículo tendrá que seguir siendo un proyecto político, social y académico 
https://doi.org/10.15359/ree.24-S.3

https://www.revistas.una.ac.cr/index.php/educare

educare@una.ac.cr

que encamine la formación de personas con pleno ejercicio de sus derechos humanos, en aras de una mayor equidad, inclusión y desarrollo de sus capacidades, en contextos que brinden el mayor bienestar y aprendizaje. Deberá cuestionarse si la estructura por disciplinas y contenidos temáticos inconexos es pertinente, o si es mejor pensar en opciones de educación centrada en la comprensión de fenómenos sociales y científicos, la producción colaborativa y situada de saberes interdisciplinares que permitan la integración del conocimiento, las experiencias de aprendizaje-servicio en comunidad, la creación artística y científica basada en proyectos, la formación dual más allá de los recintos escolares, entre otras opciones. Lo deseable es que sean currículos flexibles, de código abierto, situados, que permitan la construcción de trayectorias personales para aprender, el tránsito entre escenarios formales e informales, presenciales e híbridos. Dejemos de pensar en la normalidad o la meritocracia. Al respecto Echeita (2020) propone cambios sustantivos, porque la exclusión, la discriminación, el maltrato y el fracaso escolar se producen al interior de las instituciones educativas.

\section{En conclusión}

Si apostamos a la formación de identidades éticas, solidarias, colaborativas y corresponsables de un proyecto de sociedad más justo, hay que atender al tema de la inclusión, no solo como asunto de personas en condición de discapacidad, sino de todo tipo de colectivos. Los nuevos ambientes de aprendizaje requieren de prácticas educativas híbridas, formales e informales, que deberán transitar a enfoques de participación comunitaria, aprendizaje entre pares, modelos de diseño universal para el aprendizaje, recursos y aplicaciones que generen accesibilidad y aprendizaje con comprensión en función de la diversidad del alumnado, con apoyos tutoriales y acompañamiento, así como personalización de trayectorias curriculares.

El futuro está aquí y debemos construirlo con y para las comunidades educativas.

Agracecimiento: A la DGAPA-UNAM por el apoyo a través el proyecto PAPIIT IN301620.

Nota general: La traducción y corrección de estilo han sido realizados por las autoras.

\section{Referencias}

Corporación Andina de Fomento. (05 de julio de 2019). Cerrar la brecha digital en América Latina y el Caribe depende críticamente de la transformación de los Fondos de Servicio Universal. https://www.caf.com/es/actualidad/noticias/2019/07/cerrar-la-brecha-digital-enamerica-latina-y-el-caribe-depende-criticamente-de-la-transformacion-de-los-fondosde-servicio-universal/?parent $=6372$ 
Cuenca, R. (2012). Sobre justicia social y su relación con la educación en tiempos de desigualdad. Revista Internacional de Educación para la Justicia Social (RIEJS), 1(1), 79-93. En http://www. rinace.net/riejs/numeros/vol1-num1/art3.pdf

Echeita, G. (2020). La pandemia del Covid-19. ¿Una oportunidad para pensar en cómo hacer más inclusivos nuestros sistemas educativos? Revista Internacional de Educación para la Justicia Social, 9(1), 7-16. https://revistas.uam.es/riejs/article/view/12152

Garrison, D. R. y Anderson, T. (2005). El e-learning en el siglo XXI: Investigación y práctica. Octaedro.

UNESCO (2020, julio 15). Seguimiento mundial de los cierres de escuelas causados por el Covid-19 [Mapa]. Autor. https://es.unesco.org/covid19/educationresponse 